\title{
FORMACION, CRISIS Y TRANSFORMACION DE LA ESTRUCTURA AGRARIA DE COCHABAMBA. EL CASO DE LA HACIENDA DE PAUCARPATA Y DE LA COMUNIDAD DEL PASSO, 1538-1645 y 1872-1929
}

\author{
POR \\ ROBERT H. JACKSON \\ Universidad de Texas \\ JOSE GORDILLO CLAURE \\ Universidad de San Simón, Cochabamba
}

En la última década los eruditos han prestado una atención considerable a la evolución y a la transformación de la estructura agraria y a las relaciones sociales en la Bolivia rural anterior a la revolución de 1952, así como al decreto de reforma agraria del año siguiente que dividió las haciendas en amplias zonas del país, redistribuyendo tierras entre campesinos que no poseían ni un acre (1). Muchos analistas of recen una interpretación estructural,

SIGI.AS UTILIZADAS:

AHAC: Archivo Histórico del Arzobispado, Cochabamba

AHMC: Archivo Histórico Municipal, Cochabamba

ANB: Archivo Nacional de Bolivia, La Paz.

APC: Archivo de la Prefectura. Cochabamba

PT: Patrones de tributarios

(1) Por ejemplo, ver Silvia Rivera Cusicanoul, Oprimidos pero no vencidos. Lachas del campesinado avmara y ghechu'a 1900-1984. La Paz, 1984; Gustavo Rodricivez OSTRIA, Expansion de la hacienda o supervivencia de la commidad? Cambios en la estructura agraria boliviana del siglo XIX, Cochabamba, 1982; Brooke LaRson, Colonialism and Agrarian Trans/ormation in Bolivia: Cochabamba, 1500-1900, Princeton, 1988; Erick LAN(iER, Economic Change and Rurar Resistance in Solhern Bolivia 1880-1930, Stanford, 1989; Tristan PIATT, Estado boliviano y avllu andina. Tierra v tributo én el norle de Potosí, Lima, 1982; José Gordollio Ci.aurl: y Robert H. Jackson, Mestizaje y proceso de parcelación e'n la estructura agraria de Cochabamba (El caso de Sipe'Sipe en los siglos XVIII-XIX), HISLA 10, 1987, págs. 15-37; José Gordillo Ci.Aure, El origen de la hacienda e'n el Valle Bajo de Cochabamba. Conformación de la estritetura agraria (1500-1700), Cochabamba, Universidad Mayor de San Simón, Tesis 1988; José Gordlllo Claure, "El proceso 
relacionando el marco cambiante de la tenencia de la tierra, su explotación y la mano de obra rural, con los altibajos de la demanda en el mercado local y regional de productos agrarios, y sobre todo, con el impacto en la agricultura de ciclos en la industria minera boliviana predominante. Un segundo tema considerado es la aplicación de políticas dirigidas contra las formas colectivas de propiedad de la tierra incluyendo la ocupada por la Iglesia y por las comunidades indias, así como las distintas respuestas de los campesinos ante la erosión infligida a la base física de sus tierras como consecuencia de la aplicación de una política de inspiración anticorporativa.

Muchos estudios de la historia rural de Bolivia se centran, bien en el período colonial, bien en el periodo nacional, lo que limita la perspectiva del análisis, al impedir una evaluación comparativa del impacto de los cambios seculares a largo plazo en la estructura de las economías local, regional e internacional sobre la tenencia de la tierra, su explotación y la rentabilidad de las actividades agrarias (2). Dentro de Bolivia, la región de Cochabamba ha recibido la máxima atención por parte de los estudiosos, debido a la riqueza informativa almacenada en los archivos locales, y a la importancia de la región en la historia rural del país, - ya que fue sede de las primeras ligas de campesinos organizados (sindicatos) durante los años treinta-, las cuales ejercieron una notoria influencia en la evolución de la política de reformas agrarias en la década de los cincuenta. Sin embargo, son muchas las cuestiones fundamentales sobre la evolución y la transformación de la estructura agraria de Cochabamba a lo

de extinción del yanaconaje en el valle de Cochabamba. Análisis de un padrón de yanaconas (1692)", Revista Estudios-UMSS, 1988, n² 2, págs. 29-59; Erwin GRIES HABER, "Export Expansion and Indian Land Sales in the Department of La Paz, Bolivia 1881-1920", Ponencia presentada al Comite de Estudios Andinos, Asociación Histórica Americana, 1986; Robert H. JACKSON, "The Decline of the Hacienda in Cochabamba, Bolivia: The Case of the Sacaba Valley, 1870-1929", The Hispanic American Historical Review, 1989, no 69, págs. 259-281; y Robert H. JACKSON, "Markets, Peasantry and the Formation and Fragmentation of the Hacienda in Cochabamba, Bolivia, Peasant Studies, 1988, no 16, págs. 39-52.

El Taller de Historia Rural, de la Universidad Mayor de San Simón, en Cochabamba, está organizando actualmente proyectos de investigación sobre los precios de los mercados agrícola y de la tierra en Cochabamba durante el siglo XVIIl, censos y crédito rural, población, organización espacial. Asimismo se investiga sobre la economía regional de la villa de Oropesa (Ciudad de Cochabamba) inmediatamente después de la Independencia.

(2) Las excepciones son "Mestizaje" de Gordillo Claure y "Markets" de Jackson 
largo de cuatro siglos de historia que permanecen sin respuesta todavía, o que siguen estando oscuras.

El presente ensayo examina la evolución de la estructura agraria de Cochabamba basándose en un examen de la microhistoria de las transformaciones de la hacienda de Paucarpata y del ayuntamiento del Passo, situado en Valle Bajo, uno de los tres que constituyeron el núcleo agrícola principal de la región y de toda Bolivia hasta muy avanzado el siglo XIX. Nuestro objetivo no es otro que documentar el proceso histórico de la formación de la hacienda, la relación entre ésta y la comunidad, especialmente los conflictos con respecto a las tierras y al agua, y la dinámica del cambio en la estructura agraria de Cochabamba consiguientes a los profundos cambios estructurales en las economías local, regional e interregional de la segunda mitad del siglo pasado. El presente estudio no configura una historia continua de la hacienda y de la comunidad, sino que documenta, más bien, el proceso de formación de la economía rural de Cochabamba en los siglos XVI y XVII, así como la transformación de los modelos de propiedad de la tierra y de las relaciones de la sociedad rural a fines del siglo XIX y comienzos del XX, una vez liberalizada la economía boliviana $\mathrm{y}$ tras la crisis resultante en la agricultura de Cochabamba.

El estudio de la evolución de la estructura agraria de Cochabamba que presentamos aquí no sólo aporta más datos a la literatura relativa a la economía rural durante la reforma preagraria, sino que enriquece la historia rural de Iberoamérica. La historia de la hacienda de Paucarpata y de la comunidad del Passo ilustran tendencias que han sido confirmadas documentalmente por estudios de otras regiones de Iberoamérica. Por ejemplo, la formación de la hacienda de Paucarpata demuestra la poderosa influencia de los colonizadores españoles - a menudo se trataba de encomenderos- para conseguir fallos judiciales favorables que les adjudicaran títulos de propiedad sobre parcelas en litigio, así como la importancia de la composición de las tierras, consistente en la revisión judicial de la validez de los títulos de propiedad y en el pago de una multa como condonación de títulos defectuosos, para la consolidación de la estructura agraria emergente. El examen de Paucarpata y del Passo permite formarse una idea cabal de la evolución en las formas de mano de obra en las haciendas, en relación con las pautas demográficas, especialmente los fenómenos de migración, y los 
cambios en las condiciones de mercado sobre la rentabilidad de la agricultura (3).

El presente ensavo se divide en cuatro secciones: La primera permite una breve introducción en la economía agrícola de Valle Bajo, y va seguida por un debate sobre la política colonial de la reducción, pilar de la creación de la comunidad del Passo, y sobre la transformación de la comunidad que abocó en su abolición definitiva en la segunda mitad del siglo XIX. Las dos secciones finales pasan revista a la historia de la propiedad legal de la hacienda de Paucarpata y a su parcelación, muy avanzado ya el siglo XIX, así como también a la evolución y a la transformación del régimen de mano de obra de la hacienda, y a la organización de la producción en relación con los cambios experimentados en las condiciones de mercado. Con objeto de comprender la evolución y la transformación de la estructura agraria de Cochabamba, se hace necesario describir la situación de la agricultura en Valle Bajo.

\section{Tierra y agricultura en Valle Bajo}

Cochabamba está situada en la ladera oriental de la cordillera andina. La región central del valle se subdivide en tres valles separados, que constituyen, en realidad, el lecho de antiguos lagos, de características agrícolas diferentes y de una desigual riqueza hidráulica. Valle Bajo es el más húmedo de los tres y,

(3) En cuanto al clásico informe sobre la formación de la hacienda en México, véase Land and Society in Colonial México The Great Estate por François Chevalier, Berkeley y los Angeles, 1963. Estudios subsiguientes sobre la evolución de la hacienda han modificado el modelo de Chevalier. Con referencia a México, pueden consultarse William TAYIOR, Landlord and Peasant in Colonial Oaxaca, Stanford, 1972 y Eric VAN YouNG, Hacienda and Market in Eighteenth Century Mexico, Berkeley y Los Angeles, 1981.

Entre los estudios pioneros sobre la evolución de la hacienda en la región andina se cuentan: Manuel BuRgiA, De la encomienda a la hacienda capilatista, Lima 1976; Robert KEITH, Conquest and Agrarian Change the Emergence of the Hacienda System on the Perwivian Coast, Cambridge 1976; Estruclura agraria y vida rural en una region andina: Ollantavtambo e'ntre los siglos XVI-XIX. Cuzcio 1983, por Luis Gı.AvE y María Isabel Rimy; Landon'ners in Colonial Peru, Austin 1984, por Keith Davies; y Provincial Patriarchs: Land Tenure and the Economics of Poner in Colonial Pern. Alburquerque 1986, por Susana Ramirt:. Hasta la fecha no se ha completado ningún estudio sobre la evolución de la estructura agraria de otras regiones de Bolivia. 
permitía, y sigue permitiendo, a los hacenderos la producción de distintos tipos de cosechas con destino a los mercado local y regional. La existencia de agua facilitaba a los granjeros la obtención de cosechas más rentables. En un informe elaborado en el último decenio del ochocientos se mencionaban los beneficios producidos por las diferentes cosechas por hectárea de terreno en Cochabamba. El trigo producía 35 Bs. el maíz 100.00, la alfalfa 155.66, y los frutos y las hortalizas de los huertos 189.40 Bs. Los hacenderos de Valle Bajo se especializaron en la producción tanto de cereales como de cosechas más rentables, sobre todo alfalfa, frutas y legumbres. La inspección catastral, según reflejan los documentos de principios del siglo $\mathrm{XX}$, detalla la explotación de las tierras y su sistema de riego en Valle Bajo; los cantones del SipeSipe, Passo, Colcapirhua y Quillacollo. El maíz y otros cereales eran cultivados en 9.816 haciendas, los tubérculos en 1.429, la alfalfa en 2.125, y los frutos y las legumbres en 2.692 . 9.373 propiedades fueron irrigadas, total o parcialmente. Todas las cosechas indicadas se producían en el Passo, si bien su especialización se centraba, al parecer, en el forraje, el cual se cultivaba en 923 haciendas, ya que un $43 \%$ de todas las fincas en Valle Bajo producían alfalfa (4).

Existen varias clases de terreno en Valle Bajo. Las tierras de mejor calidad son los terrenos de aluvión regados, por lo general, por el agua procedente del rio Tocha y de otros arroyos o manantiales del valle. Este está rodeado de montañas. La falda de las montañas está destinada al cultivo de secano de granos y tubérculos, a las superficie de pastoreo o al acopio de leña y materiales de construcción, en el monte. Las tierras situadas en las montañas, o estancias, los prados y las zonas relativamente llanas se dedican al pastoreo, al cultivo de secano, sobre todo de tubérculos, y al acopio de leña y materiales para la construcción. Los ayuntamientos en Valle Bajo eran propietarios de valiosas tierras feraces y de regadío en el valle y en la falda de las montañas. Las haciendas solían ccupar los tres tipos de tierra cuyo valor difería según la zona ecológica en que estuvieran situadas. A principios de nuestro siglo el valor de una hectárea de tierra en los distritos centrales del valle de Cochabamba, fluctuaba entre 172 y 1.725 Bs. mientras que las zonas de pasto-

(4) E: Heralde, Cochabamba, 2.3 de septiembre de 1898; y Catastro de la Propiedad Rústica, APC; Provincia de Quillacollo, (antones de SipeSipe, Passo, Colcapirhua y Quillacollo. 
reo de las ticrras altas del puno (o altiplanicie) valían $8.62 \mathrm{Bs}$. por hectárea (5). Las comunidades de Paucarpata y del Passo contenían amplias extensiones de valle con terrenos fértiles cuyo valor se apreció durante los siglos XIX y XX, y que alcanzaron gran demanda en el mercado a finales del siglo pasado.

\section{LA COMUNIDAD Y LA FORMACIÓN DE MODELOS DE PROPIEDADES RÚSTICAS}

Antes de la conquista española del estado de los Incas, los distritos del valle de Cochabamba estaban escasamente colonizados, si bien ofrecian perspectivas atrayentes para un sistema estatal ávido de explotar las tierras fértiles del valle y que tenía que afrontar la hostilidad de tribus indias como la de los chiriguanos en los confines de sus dominios en la vertiente oriental de la cordillera andina. Durante el reinado del inca Huayna Capac se establecieron colonias étnicas en Valle Bajo. El estado reasentó a más de 14.000 agricultores y soldados en Cochabamba (6). Por otra parte, a finales del siglo XV, Huayna Capac distribuyó tierras en Valle Bajo entre varios grupos étnicos del altiplano, así como parcelas para la subsistencia de los campesinos y de los soldados enviados al valle (7). Esta distribución de las tierras en Valle Bajo supuso una base legal para que los nobles de las tierras altas reivindicaran sus titulos sobre las regiones del valle que, tras su conquista por los españoles en 1540, eran muy codiciadas.

Tras la llegada de los españoles al Perú y el derrumbamiento del Estado Inca, los mitmaqs (nómadas estacionales) de Valle Bajo volvieron a sus comunidades de origen, mientras que algunos grupos de mitimaes (nómadas permanentes) y de soldados se quedaron en Valle Bajo, viviendo en unos 130 caseríos distan-

(5) La caracterización de los tipos de tierra en el Valle Bajo se basa en la obra "Mestizaje", de Gordillo Claure y Jackson [1], pág. 19. La Hacienda de Paucarpata y otras haciendas comprendian estancias locali izadasen las montañas circundantes. En cuanto a los valores diferenciales de las tierras, El Heraldo, 22 de octubre de 1907.

(6) Nathan WACHTFL, "The Mitimas of Cochabamba Valley: The Colonization Policy of Huayna Capac" en George Col..IFR, y cols, editores, The Incen and Azte'c States, 1400-1800, Nueva York, 1982.

(7) Adolfo de Moral.ss, Repartimiento de tierras por el Inca Huavna Capac. Testimonio de un documento de 1556, Cochabamba, 1977. 
tes unos de otros (8). Fueron tres los españoles que recibieron títulos sobre las encomiendas de Valle Bajo: Hernando de Silva la jurisdicción de SipeSipe, con 50 tributarios y una renta anual de 16.000 pesos; a Rodrigo de Orellana se le concedió Tiquipaya, con 550 tributarios y una renta de 12.000 pesos, mientras que Passo fue otorgada a Juan de Carvajal y Alonso de Camargo. Posteriormente, el virrey La Gasca adjudicaría Passo al licenciado Juan Polo de Ondegardo, importante funcionario real (9).

En 1573, los funcionales reales empezaron a aplicar la política de reducciones en Valle Bajo, consistente en el reasentamiento de poblaciones campesinas dispersas en comunidades compactas a las que se habían asignado terrenos de labradio. La población de Valle Bajo fue ubicada en tres comunidades: SipeSipe, que retornó a la jurisdicción directa de la Corona, con un total de 819 tributarios, San Miguel de Tiquipaya, señalada en encomienda a Francisco de Orellana, con 504 tributarios, y Santiago del Passo, otorgada a Jerónimo de Ondegardo, hijo del encomendero anterior, Juan Polo de Ondegardo, con 3.298 habitantes y 684 tributarios (10).

Cada comunidad recibió los títulos de propiedad y de usufructo de una extensión determinada de terreno. La adjudicación

CuAdro 1. POLITICA DE REDUCCIONES EN COCHABAMBA, c. 1573

\begin{tabular}{lccc}
\hline & $\begin{array}{c}\text { Original de } \\
\text { Asentamientos }\end{array}$ & $\begin{array}{c}\text { Número de } \\
\text { Reducciones }\end{array}$ & Población \\
\hline SipeSipe & 52 & 1 & 3.691 \\
Passo & 48 & 1 & 3.298 \\
Tiquipaya & 30 & 1 & 2.573 \\
\hline Tapacari & 42 & 2 & 6.014 \\
Mizque & 6 & 1 & 1.343 \\
Totora & 50 & 1 & 7.036 \\
TOTAL & 228 & 7 & 23.955 \\
\hline
\end{tabular}

Fuente: Nicolás Sanchez-Albornoz. La población de Iberoamérica. Su historia.

(8) Nicolás Sánchez. Albornoz, Indios y tributos en el Alto Perú, Lima 1978.

(9) Joseph Barnadas, "Los origenes coloniales de Cochabamba", Revista de Estudios Bolivianos Kollasuvu, 1974, nº 86, pág. 24.

(10) David N. Cook, Tasa de la Visita General de Francisco de Toledo, Lima, 1975, pág. 24. 
inicial de tierras a la comunidad del Passo totalizaba 660 fanegadas de valle (11). La proporción hombre-tierra que quedó establecida en la comunidad del Passo fue de 684 tributarios por 660 fanegadas de tierra, o sea, algo menos de una fanegada de terreno regado por cada tributario. La evidencia disponible hace suponer que esta proporción resultaba generalmente uniforme en Valle Bajo, lo que permite establecer un cálculo de la extensión del valle asignada a las comunidades de SipeSipe y Tiquipaya del orden, respectivamente, de unas 786 fanegadas para la primera y de 486 fanegadas para la segunda (12) (ver Mapa 2).

La composición multiétnica de las reducciones toledanas reflejaba la política de mitmaq aplicada por Huavna Capac. El inca desalojó a la población indígena de Valle Bajo, Cotas y Chues, trasladándola a la frontera oriental de Tawantinsuyu (Estado Inca). Sólo se conservó el Soras pastoral de SipeSipe, considerado por el Inca como el único grupo étnico genuino de Valle Bajo. El resto de la población de las tres comunidades era de origen mixto. La composición étnica de las comunidades variaba a tenor de las características demográficas que presentaba cada grupo, y de las pautas migratorias anteriores y posteriores a la conquista española del Alto Perú. Tiquipaya constituye un buen ejemplo de lo que decimos. Los funcionarios reales agruparon la población de quince ayllus en Tiquipaya. De acuerdo con el censo de Tiquipaya levantado en 1573, seis de los quince ayllus pertenecían al Soras de SipeSipe, distribuidos dentro de los ayllus del Aycamaque, Sulcahavi, Collana, Ocumari, Tontoma y Malcochape. Los otros nueve ayllus eran de mitimaes de diferentes grupos étnicos: Hurinchil (sic) y Hananchilque, del grupo étnico Chilque; Puccarani de los Pacajes, Quillaca del Quillaca; Andamarca, Corocoro, y Samancha de la Caranga; Asangaro de las Collas, y ayllu Cara (13).

Cada uno de los quince ayllus reasentados en Tiquipaya tenía

(11) AHAC, Notaría Eclesiástica, Legajo 2, expediente 17. Este lítulo de propiedad, al que se hace referencia a través de la concesión de titulos por la composición de tierras, no menciona la superficie de otras tierras de control comunal fuera del ámbito de Valle Bajo. Cabe suponer que las tierras comunitarias en la serrania eran mayores en exiensión que las tierras del valle.

(12) G(ORIIII.O, |11.

(13) AHMC, Expedientes Judiciales, Legajo 95; se encontró col original de la Visita (jeneral de Tiquipava, completada por Francisco Lazarte y Molina el 20 de septiembre de 1573. Mercedes del Río, del Institute de ('ienciais Antropológicals de la Universidad de Buenos Aires, y José Gordillo (lature, del Centro de Estudios de la Población de la Universidad Mavor de San Simón, Cochabamba, han concluido un análisis preliminar del eenso elaborado como parte de la visita. 
un curaca principal. Los españoles modificaron, sin embargo, la estructura política interna de la comunidad, al nombrar tan solo dos curacas como representantes de los ayllus, étnicamente distintos, iniciativa que trajo como consecuencia un pleito judicial, que se prolongó durante mucho tiempo, incoado por los dos curacas nombrados por el visitador general Francisco de Lazarte y Molina, o sea, los curacas del Sora ayllus Aycamaque y Sulcahavi, contra los curacas del ayllus integrados en los grupos étnicos de las tierras altas, en torno al control de las tierras del Estado Inca en Valle Bajo. La política toledana, tal como se llevó a efecto en Valle Bajo, no consiguió crear la cohesión social buscada por los políticos españoles a través de la creación de nuevas comunidades, y contribuyó al abandono de las tierras asignadas por la Corona, y al reasentamiento del ayllu individual (14).

La comunidad de SipeSipe no siguió la misma pauta de dispersión una vez que se empezó a aplicar la política de reducciones, tal como se documenta con respecto a Passo y Tiquipaya, lo que cabe atribuir a una cohesión social mayor en el seno de una población de una mayor homogeneidad étnica. Por otra parte, su status de habitantes originarios de Valle Bajo permitió a los Soras de SipeSipe ejercer un control mayor sobre las parcelas asignadas a la comunidad y, desde la perspectiva del objetivo del programa toledano, aplicar un mayor grado de integración en la economía de mercado, aún en fase de desarrollo. Gracias a las grandes extensiones de tierras de labor debidamente irrigadas, a una mano de obra abundante y a una situación central con respecto al dinámico mercado de Potosí, la economía de la comunidad de SipeSipe llegó a florecer en las últimas décadas del siglo XVI, cuando la venta de los excedentes de maíz permitió la acumulación de grandes cantidades de dinero en su Caja de Comunidad. Sin embargo, ésta no resultaba inmune ni a las exacciones del Estado colonial ni a los manejos de los prominentes colonos locales. Los funcionarios reales hicieron préstamos con interés, procedentes de los fondos de la comunidad, a los terratenientes locales, los cuales, con frecuencia, no fueron de-

(14) En 1593, veinte años después de la reducción toledana, Fray Luis López. de Solis, obispo de Quito, mientras efectuaba una visita y una composición de tierras, trató de reasentar los avllus de Passo y Tiquipaya que habían sido transferidos a los distritos de Londo, Carasa, Quillacollo, y las alturas de Apote. López de Solís concedió a los curacas de los ayllus individuales seis días para volver a Tiquipaya y Passo bajo la amenaza de destruir sus casas, y de vender sus tierras, en realidad baldios de la Corona. AHMC, Expedientés judiciales, Legajo 22. 
vueltos sino al cabo de muchos años (15). Por otra parte, mediante una serie de mecanismos diversos, las tres comunidades perdieron una cantidad considerable de tierras en el año 1645, fecha en la que José de la Vega Albarado realizó una visita y una composición de tierras en Valle Bajo, validando títulos defectuosos sobre tierras que habian sido reivindicadas por hacenderos (16).

El proceso de la consolidación de la propiedad rural en Valle Bajo duró aproximadamente un siglo, y concluyó únicamente con la visita de 1645. Las primeras generaciones de colonos que se asentaron en la región de Cochabamba después de 1538 estaban vinculadas con las economías mineras de Potosí y Porco y con la incipiente burocracia colonial, y ya desde los albores de la colonización española de la región, empezaron a organizar empresas comerciales para la producción de artículos alimenticios destinados al suministro de los centros mineros. Los primeros terratenientes aplicaban estrategias diversas para la expropiación y el control de la tierra, lo que acabó moldeando el carácter de la aristocracia rural local. La reorganización territorial que surgió

(15) En septiembre de 1717, los curacas de la comunidad de SipeSipe solicitaron a los funcionarios judiciales locales que gestionaran la recuperación de 6.194 pesos, prestados a terratenientes españoles entre 1577 y 1586 , préstamos garantizados por censos que se habian levantado en diez chacras. AHMC, Actas notariales, Legajo 100.

(16) En AHMC, Actas Notariales, Legajo 70, se encuentran los títulos compuestos por José de la Vega Albarado. De acuerdo con un informe de Pedro Pérez. Arias, se vendieron alrededor de 300 fanegas de la comunidad SipeSipe a distintos compradores, con inclusión de 65 fanegadas que adquirió el propio Arias. Se registraron tres adquisiciones importantes de tierras de la comunidad de Tiquipaya: la adquisición de 70 fanegadas de tierra por parte de Gregorio Velázquez de Puga, 100 fanegadas adquiridas por Pedro Navarro, y 50 por Juan Rodríguez Castellano. Las ventas de suelo de la comunidad de Passo comprendieron una parcela de 93 fanegadas a Luis de Guzmán, y 30 fanegadas a Juan Rodríguez Castellano. Las comunidades en el Valle Bajo seguian disponiendo de una cantidad considerable de tierras hacia fines del período colonial, a pesar cle las usurpaciones de los terratenientes españoles. Segun un informe elaborado en 1826, SipeSipe seguía disponiendo de 682 fanegadas de tierra, Passo de 557, y Tiquipaga de 620.

Esas cifras se citan en Economic Decline and Social Change in an Agricultural Hinterland: Cochabamba (Bolivia) in the Late Colonial Period de Brooke LaRSON, Universidad de Columbia, Tesis Doctoral, inédita, 1978, pág. 337. La aparente disparidad en la cifra relativa a la cantidad de tierras asignadas a la comunidad de Passo en 1826, y las propiedades afectadas por la composición de tierras én el distrito de Passo en 1646 pueden atribuirse al hecho de que se asignaran parcelas a la comunidad, que estaban situadas en el valle, la falda de la montaña y la serranía. La cifra de 660 fanegadas de tierra comunitaria comprende sólo las tierras situadas en el valle. Además, con la enajenación del suele del valle, es posible que se haya asignado a las comunidades tierras de menor calidad dad en la serrania, tal como indica RAmíREz. [3], que se hizo con las comunidades de la costa nortc del Perú. 
de las reformas toledanas de 1570, destinadas a subvencionar de distintas maneras a la economía minera, mermando simultáneamente el poder económico y político de los encomenderos, redefinió la estructura naciente de la propiedad rural en Valle Bajo, delimitando explícitamente el área de futuro desarrollo de las haciendas privadas y de los terrenos que iban a reservarse a las comunidades (17). La consolidación de la propiedad rural en Valle Bajo coincidió con la época de máximo esplendor de la minería de Potosí, que se extendió desde mediados del siglo XVI, y abarcó la mayor parte del siglo XVII. El auge de Potosí generó una actividad comercial muy dinamizada hacia la producción de artículos alimenticios y de otras mercancías para consumo de una población urbana en fase de rápido crecimiento, y de los numerosos núcleos indígenas que, habiéndose asentado en el cinturón de Potosí, servían como reserva para el reclutamiento de mano de obra minera y para otras actividades afines. La primera generación de encomenderos, mercaderes y mineros que pusieron las bases de una agricultura de orientación comercial en Valle Bajo, y complementaria de otras actividades económicas, dio lugar, durante el período de florecimiento de Potosí, al nacimiento gradual de una nueva clase de terratenientes locales cuva principal ocupación era el cultivo del campo, y cuyos contactos con la economía minera se reducían a la venta de productos agrícolas. Esta aristocracia propietaria del suelo monopolizaba prácticamente el abastecimiento alimenticio de Potosí y La Plata.

El crecimiento de la demanda de artículos agrícolas de Cochabamba y la depuración del título de propiedad a través de la composición de tierras elevaron el precio de los terrenos destinados a la agricultura, así como el deseo de adquirir tierras. Comenzó a desarrollarse un dinámico mercado de terrenos, que enriqueció a todos aquellos capaces de entregarse a la especulación y a la monopolización de los suministros. Después de 1645 se produjo un auge en la venta de parcelas de pequeña y mediana extensión, denominadas chacras, para distinguirlas de las hacien-

(17) Glave y Remy, describen en [3], pág. 79, un proceso semejante con respecto al valle de Ollantavtambo (Perú). Nos gustaría reiterar la importancia de la demarcación de las tierras comunitarias en la formación de la estructura de la tenencia del suclo en Valle Bajo. En 1571 y de nuevo en 1574, el virrey Francisco de Toledo ordenó la fundación de la Villa de Oropesa, ciudad de Cochabamba. La villa no fue fundada oficialmente mientras no se hubiera concluido la demarcación de las tierras comunitarias. Sólo se podian otorgar a los colonizadores españoles tierrass no asignadas a las comunidades. Ver José Gordollo Cl.Aure y Carlos Lavayen, "Población y estructura urbana en la ciudad de Cochabamba, 1826-1831, Revista Estudios-iMSS, n" 4. 
das mavores. La gráfica mimero 1 muestra el ritmo de venta de esos terrenos, que alcanzó su punto máximo en 1670. La gráfica 2 indica la relación entre el precio y la cantidad de tierra vendida. El precio de la tierra aumentó desde alrededor de 120 pesos por fanegada hacia 1645 , a 250 pesos en la época de máxima demanda cuando el mercado era un mercado de vendedores, cayendo en el siglo siguiente al nivel aproximado de 1645. Además, la superficie media de las parcelas vendidas descendió a diez fanegadas aproximadamente en 1670, patrón que se mantuvo durante los cien años siguientes (18).

Las características del mercado del suelo apuntan a un elevado grado de monopolización en manos de un pequeño número de familias hacendadas, pero también a la aparición y supervivencia de un grupo numeroso de latifundistas particularmente activos. Por lo general, las grandes haciendas se encontraban cerca de la falda de las montañas y próximas a las comunidades de los indios, mientras que las chacras crecían a una gran distancia de la cordillera, es decir, a una distancia aún mayor de donde sus últimas estribaciones llegaban al fondo del valle. Quienes controlaban el suministro de agua, en este caso los grandes hacenderos y los jefes de la comunidad, podian garantizar una provisión mayor de agua de riego que los chacareros, que se habían asentado aguas abajo. Los primeros conflictos entre los hacendados y las comunidades se produjeron en torno al control del suministro del agua, y no en torno a disputas por el dominio de la tierra, y los chacareros, que habían fijado sus reales en torno a la ciudad de Quillacollo, se quejaban continuamente que las haciendas y las comunidades utilizaban demasiada agua y les dejaban poquísima para sus propias cosechas.

A finales del período colonial, el modelo de propiedad rural existente en Valle Bajo era bastante complejo, como había quedado tipificado por la hacienda de Paucarpata y la comunidad del Passo en el distrito de este nombre (el cantón de jurisdicción administrativa republicana del Passo). Si bien la comunidad experimentó una pérdida significativa de su base física quedaba todavía una extensión considerable de tierras que garantizaban y aseguraban la subsistencia de una población campesina india que había quedado considerablemente mermada. Por otra parte, la estructura de las propiedades rurales que se desarrolló gradualmente en los siglos dieciséis y diecisiete se mantuvo bastante estable hasta finales del siglo diecinueve, como demuestran el

(18) Gordil.lo Claure, [1] págs. 207-226. 
lento aumento de las propiedades privadas hacia la mitad del siglo pasado y su rápida multiplicación en el Cantón del Passo en las últimas décadas del diecinueve y en el primer tercio de nuestro siglo. La subdivisión y la venta de las tierras comunitarias tras la aprobación, en 1874, de la ley de exvinculación, desempeñaron un papel importante en el aumento del número de propiedades privadas.

La estructura interna de las comunidades en Valle Bajo experimentó cambios en las postrimerias de la época colonial y a principios del período republicano. Cabe mencionar, a guisa de ejemplo, la política estatal a fines de la década de 1780 , implantada por el intendente Francisco de Viedma y reanudada en 1944, de conversión del régimen fiscal de los forasteros residentes en las comunidades, por la que se les equiparaba a los originarios y se les concedía plenos derechos sobre el suelo comunitario, incrementándose así los ingresos fiscales del Estado. Continuaron existiendo, sin embargo, dos categorías de tributarios en 1870, con posibilidades, sin embargo, de acceso desigual a las tierras comunitarias. Passo quedó dividido en dos mitades, la anansaya y la urinsaya, distribuyéndose el suelo entre los originarios y los cajoneros (forasteros) (ver tabla 3).

Ochenta y tres originarios ocuparon parcelas de una extensión media de 8.26 hectáreas de terreno en anansaya, mientras que setenta y siete cajoneros explotaron parcelas de una extensión media de 1.61 hectáreas. Cuarenta y cuatro originarios y un número igual de cajoneros constituían la mitad de la urinsaya, y ocuparon parcelas de una extensión media de 8.77 y 0.86 hectáreas respectivamente (19). La cantidad de tierras a la disposición de los cajoneros no garantizaba, probablemente, su autosuficiencia (de hecho, un autor estimaba que una familia de campesinos necesitaba 2 hectáreas de tierra de cultivo de excelente calidad para subvenir a sus propias necesidades alimenticias) ni producía una renta suficiente para el pago de sus obligaciones tributarias, por lo que el trabajo en las tierras de los originarios o las peonadas estacionales en haciendas contiguas podría haber resultado un complemento necesario de sus actividades agrícolas (ver cuadro 2).

El Estado de Bolivia inició un ataque sistemático a las comu-

(19) "Entre reformas y contra reformas. Las comunidades indigenas en el Valle Bajo de Cochabamba", por (Gustavo Romricillaz Ostria, Simposio de Las communidades indigena e'n la regionn andina durante el siglo XIX, Quito, marzo de 1989, pág. 10. 
nidades en las décadas de los sesenta y los setenta del siglo pasado. El Presidente Mariano Melgarejo (1864-1871) decretó la venta de tierras comunitarias en 1866, y las ventas en el departamento de Cochabamba entre 1867 y 1870, de las cuales la mayoría se realizó en las comunidades localizadas en Valle Bajo, totalizaron 269.705 Bs. En 1870, año durante el cual las ventas en Cochabamba rindieron un total de 234.319 Bs. (un $87 \%$ de todas las ventas), el gobierno vendió casi una cuarta parte del suelo de la comunidad del Passo (20).

Melgarejo perdió el poder tras una revolución política en la que intervinieron miles de miembros comunitarios, y el nuevo gobierno devolvió las tierras enajenadas entre 1867 y 1870. Sin embargo, esto sólo constituyó un respiro para las comunidades. En 1874, el Congreso boliviano aprobó una ley de ex-vinculación que obligaba a los miembros comunitarios a adquirir un título de propiedad individual de las parcelas que ya estuvieran explotando. El patriciado local se aprovechó de la nueva ley y de su normativa correspondiente para adquirir antiguo suelo comunitario, recurriendo, a menudo, al fraude o a la coerción. Es oportuno señalar que los residentes comunitarios de Valle Bajo apoyaban, aparentemente, el proceso de distribución de los títulos individuales, y que Valle Bajo vivió en calma y tranquilidad el período de distribución de los títulos, siendo así que en otras

CUADRO 2. ESTRUCTURA INTERNA Y DISTRIBUCION DE LA TIERRA EN LA COMUNIDAD DEL PASSO, 1844

\begin{tabular}{lcccc}
\hline Parcialidad & $\begin{array}{c}\text { Número de } \\
\text { originarios }\end{array}$ & $\begin{array}{c}\text { Hectáreas } \\
\text { de tierra }\end{array}$ & $\begin{array}{c}\text { Cajoneros } \\
\text { (Forasteros) }\end{array}$ & $\begin{array}{c}\text { Hectáreas } \\
\text { de tierra }\end{array}$ \\
\hline $\begin{array}{l}\text { Anansaya } \\
\text { Urinsaya }\end{array}$ & 33 & 685.77 & 77 & 123.68 \\
TOTAL & 44 & 386.06 & 44 & 37.90 \\
\hline
\end{tabular}

Fuente: Gustavo Rodríguez. Ostria, "Entre reformas y contra reformas: Las comunidades indigenas en el Valle Bajo cochabambino" ponencia presentada en el simposio de "Las comunidades indigenas en la region andina durante el siglo XIX», Quito, marzo 1889, pág. 10.

(20) Idem. págs. 26-27. 
regiones de Bolivia, los campesinos resistieron activamente a las comisiones rurales despachadas al campo para medir las tierras y distribuir los títulos de propiedad individuales sobre suelo comunitario (21).

Se registró un rápido crecimiento en el volumen del mercado del suelo al final de la década de los setenta, el cual se prolongó hasta las postrimerías de los noventa y, como se ha indicado más arriba, un aumento en el número de propiedades privadas dentro de la jurisdicción administrativa del Cantón del Passo (ver Tabla 3 ). Gente de todas clases compró terrenos. Sin embargo, el desmembramiento de los terrenos comunitarios no supuso una expansión de las haciendas existentes o la creación de nuevos latifundios, como ocurrió en el altiplano boliviano. Algunos miembros de la aristocracia local adquirieron tierras. Los grandes terratenientes adquirieron hasta un $42 \%$ del suelo comunitario del Passo de los terrenos que se habían vendido, de hecho, entre 1878 y 1900. Campesinos sin tierras, pequeños granjeros, comerciantes, vendedores ambulantes y artesanos, se quedaron con otro $47 \%$ de las tierras de la comunidad del Passo enajenadas durante el mismo período (22). No obstante, un poco más de un tercio (34 \%) del antiguo suelo de la comunidad del Passo había quedado sin vender en el año 1900, y en manos de miembros de la comunidad que, en calidad de terratenientes, se habían incorporado a la creciente población de minifundistas que formaban un campesinado culturalmente homogéneo, conocido localmente con el nombre de piqueros (23).

La adquisición de antiguas tierras comunitarias por grandes terratenientes no constituyó una expansión de las haciendas existentes ni la creación de unidades coherentes de producción (24). El caso específico de expansión de la base física rural de José Salamanca y de su familia, que compraron terrenos en un distrito del territorio comunitario del Passo, conocido con el nombre de Pandoja y Pocpocollo, es ilustrativo del proceso de transformación del régimen de propiedad del suelo de esa comunidad. Es relativa-

(21) Sobre los cambios en la tenencia de tierras en otras regiones de Bolivia después de 1874, ver Jackson, Decline [1], págs. 276-277.

(22) Rodriciuez, [19], pág. 35.

(23) Valoración basada en mi reelaboración de las cifras facilitadas por Rodrigue\% Ostria relativas a la superficie vendida de las tierras comunitarias del Passso entre 1878 y 1900, y la superficie de suelo controlada por la comunidad en la decada de 1870, antes de que se emperaran a vender las tierras comunitarias. Sin embargo, Rodriguez no incluyó el número de transacciones individuales, que permitiria calcular el tamaño medio de las parcelas puestas a la venta.

(24) ANB. Padrones de Tributarios, Cercado Provincia, 1844. 
mente poco lo que se sabe sobre la familia de los Salamanca con anterioridad a su elevación a la preminencia, pasado el año 1860, como aristócratas terratenientes. Hubo un José Salamanca que, allá por 1840, ya poseía terrenos en Recoleta y Chimba en los suburbios de la ciudad de Cochabamba, y que todavía compraría propiedades en la principal región agrícola de Valle Bajo. José Domingo Salamanca, patriarca de la familia y padre del futuro presidente de Bolivia, Daniel Salamanca, realizó su primera gran transacción de tierras en 1863, adquiriendo una porción notable de la hacienda, procedente de la era colonial, Collpapampa, en el Cantón Tiquipaya, situado también en Valle Bajo (25). En el transcurso de los veintisiete años siguientes, Salamanca adquirió tierras por todo Valle Bajo, incluyendo un número de pequeñas, medianas y grandes parcelas en el distrito de Pandoja y Pocpocollo.

CUADRO 3. SUPERFICIE ESTIMADA/REGISTRADA (EN HECTAREAS) DE LAS TIERRAS COMUNITARIAS DEL PASSO Y NUMERO DE PROPIEDADES PRIVADAS EN EL DISTRITO/CANTON DEL PASSO EN LOS AÑOS INDICADOS

\begin{tabular}{lcc}
\hline Año & $\begin{array}{c}\text { Superficie estimada/Registrada de } \\
\text { tierras comunitarias (en hectáreas) }\end{array}$ & $\begin{array}{c}\text { Número de } \\
\text { propiedades privadas }\end{array}$ \\
\hline 1573 & 1.914 & - \\
1692 & 1.550 & - \\
1715 & 1.615 & $\overline{-}$ \\
1826 & 1.287 & 12 \\
1844 & 1.233 & 99 \\
c. 1878 & - & 1.638 \\
1881 & - & 1.775 \\
c. 1900 & - & 2.506 \\
c. 1912 & - & -506 \\
\hline
\end{tabular}

Fuentes: Robert H. Jackson, «Modernización Económica y Transformación Agrar ia en Bolivia: El Caso de Cochabamba, 1860-1929", manuscrito no publicado, págs. 78, 88; Robert H. Jackson, «Mercados, Campesinado, y Formación y Fragmentación de la Hacienda de Cochabamba. Bolivian, Estudios sobre el Campesinado 161988 , pág. 49; José Gordillo Claure, "El origen de la hacienda en el Valle Bajo de Cochabamba. Conformación de la estructura Agraria (1550-1700)m. Tesis no publicada. Universidad Mayor de San Simón, 1987, passim: Gustavo Rodrigue\% Ostria, "Entre Reformas y contra reformas: Las comunidades indigenas en el Valle Bajo cochabambino" ponencia presentada en el simposio "Las comunidades indigenas en la región andina durante el siglo 1m. Quito, mar\%o 1989, págs. 10, 41; y Cattastro de la Propiedad Rústica, Archivo de la Prefectura de Cochabamba; Provincia de Quillacollo, Cantón del Passo.

(25) AHMC, Actas Notariales de Cochabamba, 1863. 
José Salamanca compró alrededor de 69 hectáreas de terreno situado en el distrito de Pandoja y Pocpocollo a antiguos miembros de la comunidad de Passo durante los setenta y los ochenta (26). También se hizo con otras tierras de origen comunitario en ese mismo distrito, procedentes de propietarios no indios. Así, por ejemplo, en 1890, José Salamanca pagó a Aurelia Hinojosa 3.200 Bs. por una propiedad de una superficie de 12.11 hectáreas (27). En la fecha de su muerte, acaecida en 1890, el mayor de los Salamanca era dueño de veintidós parcelas separadas en el distrito, las cuales, reunidas, sumaban 88.45 hectáreas de superficie. La mayor de ellas comprendía 24.09 hectáreas de terreno, y diecinueve no bajaban de las cinco (28). Los herederos de José Salamanca continuaron adquiriendo suelo en el distrito durante la década de los noventa, sobre todo su viuda Manuela Urey de Salamanca. En 1904, Urey de Salamanca, que había heredado las tierras de Pandoja y Pocpocollo de su marido, poseía 14 parcelas separadas, con una superficie total de 120.74 hectáreas, o sea, el $73.5 \%$ de la tierra agrícola del distrito de Pandoja y Pocpocollo, como se indica en el registro catastral elaborado a mediados de 1920. La parcela individual mayor cubría una superficie de 67.29 hectáreas (29).

¿Constituyó la adquisición de antiguas tierras comunitarias en Valle Bajo una expansión de los latifundios y un atrincheramiento de la nobleza terrateniente local? Son varios los factores que deben considerarse al responder a esta cuestión. En primer lugar, igual que ocurrió con las compras de la familia Salamanca, hubo un porcentaje significativo de antiguos terrenos comunitarios que fueron vendidos y vueltos a vender en pequeñas parcelas, de una extensión que apenas si garantizaba un nivel básico de subsistencia a la unidad familiar campesina, y que no era la ideal para el tipo de agricultura comercial caracterizado por la explotación de la tierra sobre una base extensiva y en un sistema de baja productividad, que es el que se practicaba en las haciendas de la región (30).

(26) Rol)Ricilliz, [35], pág. 36.

(27) AHMC, Actas Notariale's de Cochabamba, 1890.

(28) AHMC, Escrituras Públicas, Expediente 154.

(29) APC, Registro de Derechos Reales; Provincia de Tapacari y Quillacollo, 1904; asi como (atastro de la Propiedad Rústica, Provincia de Quillacollo, Cantón de Passos.

(30) Con respecto a la mano de obra en las haciendas de Cochabamba, consultar la obra de Rober. H. Jackson, "Evolución y persistencia del colonaje en las haciendas de Cochabamba", Siglo XIX, 1988, vol. 3, n"6, págs. 145-162. 
No se dispone de información fidedigna directa sobre la forma de gestión y de explotación del suelo de las fincas de los Salamanca en el distrito de Pandoja y Pocpocollo. Los inventarios existentes de las haciendas y las valoraciones de las propiedades de la familia Salamanca que, en el caso de otras haciendas de la región de Cochabamba registran la obligación de prestación personal de los arrendatarios de servicio, no contienen datos sobre la organización de la producción en las propiedades del distrito de Pandoja y Pocpocollo. Sin embargo, pueden hacerse deducciones a partir de las informaciones disponibles sobre otras haciendas en Valle Bajo, que incluye una hacienda importante adquirida por los Salamanca. Lo más probable es que éstos explotasen directamente las propiedades de superficie media y grande y que arrendaran, explotándolas en régimen de aparcería, las parcelas pequeñas a arrendatarios de servicio que aportaban la mano de obra para la producción en las fincas mayores, como ocurría en el terreno de más de 60 hectáreas en el distrito de Pandoja y Pocpocollo. De esta forma, los Salamanca habrían podido hacerse con mano de obra barata y reducir así los costos de producción durante un período en el que los mercados de cereales se mostraban inestables y con tendencia a la regresión. No es probable que todas las propiedades hubieran sido organizadas como una unidad de producción independiente, sino que formaban parte de un sistema que contribuía mano de obra a aquellas comarcas lo suficientemente grandes como para poder resultar explotadas provechosamente.

La nobleza terrateniente de Cochabamba padeció una importante crisis financiera en la década de los noventa, producto de diversos factores como la liberalización del comercio tras la Guerra del Pacífico (1879-1884), la terminación en 1892 del primer ferrocarril entre la ciudad costera de Antofagasta y Oruro, en el Altiplano, con la consiguiente reducción espectacular de los costos de transporte entre las regiones altas y las marítimas, la importación a Bolivia, a precios baratos y por vía férrea, de harina de trigo y de otros cereales de calidad superior, primero de Chile y, más tarde, de Norteamérica, acompañada por el descenso en la venta de harina y granos de Cochabamba, el problema del endeudamiento creciente originado por el aumento del nivel de la deuda de las propiedades rurales en las últimas décadas del siglo diecinueve $y$, finalmente, la reducción de las rentas agrícolas que 
hacían cada vez más difícil cumplir con las obligaciones pendientes. La composición del grupo propietario de la hacienda de Cochabamba cambió entre los años setenta y comienzos del siglo veinte, ya que muchos hacenderos perdieron sus fincas por la extinción del derecho de redención de sus hipotecas, o por que liquidaron sus tierras para salvar parte de sus activos y evitar la ruina total (31). En las décadas de los setenta, ochenta y noventa, tomaron cuerpo, desgajadas del antiguo suelo comunitario, fincas de superficie reducida y media, pertenecientes, por lo general, a miembros de la nobleza hacendada de la época anterior a 1870. En muchos casos, los nuevos terratenientes eran gente que, como los Salamanca, quería enriquecerse y se aprovechaba de las oportunidades surgidas al hilo de la división de las comunidades y de la crisis económica de los años noventa, para adquirir grandes extensiones de terreno a precios favorables en un período de tiempo relativamente corto. La nueva estructura de la propiedad de la tierra que surgió a finales del siglo diecinueve no consiguió estabilizarse durante las tres primeras décadas de nuestro siglo, aumentando el volumen de ventas de las pequeñas parcelas y prosiguiendo el proceso de fragmentación del suelo dedicado a la agricultura (32). Hacia los años veinte de nuestro siglo se habían censado más de 2.500 propiedades en el Cantón del Passo, y gran parte de las antiguas fincas comunitarias se encontraba en manos de pequeños propietarios campesinos, y no de latifundistas.

El dinero para la adquisición del suelo procedía de diversas fuentes. Los campesinos participaban activamente en la economía de mercado local, y vendían sus excedentes agrícolas o se contrataban como mano de obra a grandes terratenientes en trabajos estacionales, para ahorrar dinero y adquirir así, tierras. Por otra parte, se registraba un significativo flujo migratorio desde Cochabamba, potenciado por graves crisis ecológicas, de aparición periódica, en la región, y por los salarios relativamente altos que of recían la industria minera del estaño en el altiplano boliviano, las minas del norte de Chile y las plantaciones azucareras del

(31) Ver Déline, de Jackson $|1|$.

(32) Sobre la expansión del mercado rústico en Valle Bajo y el modelo de parcelación de las antiguas tierras comunitarias de SipeSipe trata "Economic Modernization and Agrarian Transformation in Bolivia: the Case of Cochabamba, 1880-1929", de Robert H. JA(kson, manuscrito inédito, cap. 6. 
norte de Argentina (33). Finalmente, el mercado de créditos en Cochabamba creció a finales del siglo diecinueve, $y$ bancos $y$ prestamistas facilitaban créditos para adquirir tierras y financiar la producción. Sin embargo, las malas cosechas consiguientes a las sequias y a otros fenómenos ecológicos, el aumento de los niveles impositivos, así como las fluctuaciones experimentadas en la demanda de productos agricolas de Cochabamba se tradujeron en el incremento del número de extinciones del derecho de redención de hipotecas que inundaban el mercado del suelo y que, durante cortos periodos de tiempo, así, a finales de la década de 1920, forzaron los precios a la baja. Finalmente, algunos grandes terratenientes liquidaban sistemáticamente sus tierras para conservar, por lo menos, una parte de sus propiedades (34).

Las haciendas fueron apareciendo al unísono con los ayuntamientos en la primera época colonial, creándose una relación de simbiosis, interexplotación y situaciones conflictivas. Los terratenientes españoles influyentes aprovecharon su poder y su prestigio en la región para usurpar las tierras de la comunidad y los derechos sobre explotación del agua, tomar dinero prestado sobre los fondos comunitarios, y emplear, con carácter estacional, mano de obra excedentaria procedente de los ayuntamientos. Sin embargo, la nobleza terrateniente sufrió pérdidas consiguientes a crisis ecológicas periódicas y a las condiciones cambiantes del mercado, por lo que la propiedad de la hacienda no podia considerarse como algo particularmente estable. Por otra parte, la hacienda como forma de propiedad sobre la tierra y como unidad

(33) En 1914, la cifra oficial de bolivianos que vivía en la Argentina era de 17.993. La mayoría estaba concentrada en Jujuy $(70.7 \%)$ y Salta $(22 \%)$. El grueso residía en el campo (96.7\%), y la plantilla laboral de tres grandes plantaciones de azúcar de Jujuy estaba constituida exclusivamente por inmigrantes bolivianos, muchos de los cuales procedian de Cochabamba. Los propietarios de las plantaciones expedian a Bolivia contratistas que se encargaban alli de reclutar a los braceros. En 1970, eran 21.968 los bolivianos que residian legalmente en Chile, la mayoria en el norte, un $57 \%$ en Tarapacá, un $14.2 \%$ en Tacna y un $26.5 \%$ en el antiguo territorio boliviano de Antofagasta. Un total del $71.2 \%$ de los residentes bolivianos de Chile vivían en el antiguo territorio peruano. Consultar al respecto el Tercer Censo Nacional de Argentina, levantado el I de junio de 1914: poblacionti. Buenos Aires, 1916; Censo Nacional de la Repriblica de Chile levantado el 28 de noviembre de 1907, Santiago 1908; y El Heraldo, Cochabamba, Bolivia, 28 de octubre de 1925. Sobre las crisis ecólógicas en Cochabamba, véase Décline, de JACKSON [1].

(34) Jackson, Decline |1], págs. 270-275. La rápida fragmentación de las tierras agrícolas no se limitaba a zonas controladas por los avuntamientos. Entre la década de 1830 y el comienzo del siglo veinte, el número de propiedades privadas en el Valle de Sacaba aumenté de 32 a 4.597 c. 1912. El período de máximo desarrollo en el número de pequeñas propiedade's conincidiós con la fragmentación de las tierras comunitarias. 
de producción se batió en retirada con la transformación de la economía a finales del siglo diecinueve, fenómeno que abocó a una inestabilidad en el régimen de propiedad del suelo y a una división de las fincas que habían surgido durante el período colonial. En la sección siguiente se traza un perfil de la historia de la formación y de la división de la hacienda de Paucarpata, situada en los confines de las tierras del ayuntamiento de Passo.

\section{FORMACIÓN Y DIVISIÓN DE LA HACIENDA DE PAUCARPATA}

La Hacienda de Paucarpata, creada por un encomendero influyente en los confines del principal ayuntamiento situado dentro de la jurisdicción de la encomienda, era una de las mayores que llegaron a formarse en Valle Bajo en los siglos dieciséis y diecisiete. A mediados del siglo dieciséis, el Licenciado Juan Polo de Ondegardo recibió en encomienda a los indios que residían en el distrito del Passo. Durante el primer período de la colonización española en Cochabamba, Polo de Ondegardo se valió de su influencia para obtener también el título de propiedad y control de las tierras situadas dentro del distrito de la encomienda. En un principio, Polo de Ondegardo se hizo con los derechos de propiedad del agua del río Patata en el punto de acceso del río al valle, donde abrió un sistema de canalización y levantó molinos de agua, así como con los derechos sobre el suelo de la margen occidental del Río Patata, frente a las tierras comunitarias (35).

La visita realizada en 1573 confirmó a Gerónimo de Ondegardo, hijo de Juan Polo de Ondegardo, en su título de propietario de la encomienda del Passo durante una segunda vida. Gerónimo de Ondegardo también consiguió, mediante su influencia sobre el Juez Visitador, situar los límites de las tierras de la comunidad de Passo en la ribera oriental del río Patata, confirmando así sus títulos de posesión sobre las tierras de Paucarpata en la orilla

(35) "Lo otro... quitaron el dicho arroyo de su curso... que era por cerca del dicho pueblo del Passo y contra su voluntad la hizo llevar el Licenciado Polo de Ondegardo por donde ahora va, con halagos y otras cosas que hizo a los caciques e indios que entonces era como su encomendero... diciéndoles... que cuando quisiesen podrán traer dicha agua al pueblo y que no era perjuicio y que era mejor se hiciese el molino de compañía... y con ello atrajo su voluntad y consintieron... y porque los indios no la tomasen y la volviesen a llevar a su pueblo se hizo hacer un margen y paredón". En "Memorial y relación que presentan los indios del Passo al Rey don Felipe il, aduciendo perjuicio por el uso de las aguas del río Patata por parte de Jerónimo de Ondegardo, vecino y propietario de la hacienda de Paucarpata", AHMC, AR 1540. Expedientes Judiciales, 1568-1674. 
opuesta del río. Veinte años después, en 1539, el obispo de Quito, Fray López de Solís, convalidó los títulos de propiedad de Ondegardo el joven sobre las tierras de Paucarpata: 99 fanegadas de terreno irrigado, 100 fanegadas de pastos, 15 fanegadas de suelo situadas en la falsa de la sierra de Moxos adquiridas de Pedro de Marquina, y 3 fanegadas en el territorio de la comunidad de Passo adquiridas de Inés de Marquina, mujer de Pedro Marquina e hija de un curaca de la comunidad del Passo (36).

La confirmación del título de propiedad de 217 fanegadas de tierra (aproximadamente 629 hectáreas, 1 fanegada $=2.90$ hectáreas), incluvendo el aprovechamiento de la principal fuente de agua de la Quebrada de Chocaya, costó 2.000 pesos pagaderos al Tesoro Real en Potosí. El bajo precio pagado por la confirmación del título hace pensar que el fraude ocurrió en las operaciones de transacción, sospecha confirmada por los problemas a los que tuvo que enfrentarse un nuevo propietario de la hacienda, Francisco Mateos Carrasco cuando trató de convalidar sus derechos de propiedad sobre la hacienda durante la visita de 1645. A pesar de haber pagado un precio de compra de 50.000 pesos por la propiedad, Carrasco se quejó de que la hacienda carecía de título legal (37). El Juez Visitador, José de la Vega Albarado, ordenó que se efectuara una medición de las tierras reivindicadas por Carrasco, y legalizó el título de 244 fanegadas de tierra (aproximadamente 708 hectáreas), ó 27 fanegadas (alrededor de 78 hectáreas) de tierra, incorporadas desde la última visita en 1593 (38).

(36) "Visita y Composición de los títulos de la hacienda y estancia de Paucarpata y Marquína ejecutado por instrucción de don Pedro de Toledo y Levva, Marqués de Mancera, virrey del Perú, que realizó el Jué Visitador de Tierras, don José de la Vega Albarado, en favor del propietario don Francisco Mateos Carrasco", AHMC, Actas Notariales, Legajo 9, 1690-1778.

(37) “... hago presentación ante vuestra merced de esta escritura pública de venta por la cual don Juan Hurtado de Cartagena consta me vendió la chacra y tierras nombrada Paucarpata en el valle grande, con la acción de servicio de mita y agua y tierras que fueron de Marquina y estancia y potrero y molino $y$ otros aperos y cosas que refiere la dicha escritura en precio de 50.000 mil pesos de a ocho reales ..., Compelido el vendedor, trajo unos títulos de cierto litígio v pleito que tuvo los indios, inserto en él una provisión v confirmación del gobierno de la composición que don Gerónimo de Ondegardo hizo con el señor obispo de Quito de estas tierras y haciendas en cantidad de 2.000 pesos corrientes que se obligó a pagar y meter en la real caja de Potosi, por no constar estar pagadas las tierras quedaron hipotecadas...", AHMC, Actas Notariales, Legajo 9, 1690-1778.

(38) Otras cinco fanegadas compuestas por Ondegardo no fueron legalizadas: "Y por cuanto a las cinco fanegadas que la medida refiere está posevendo por venta del general Pedro de Mercado, otorgado en favor del dicho don (jerónimo de Ondegardo... por escritura de 13 de julio de 1594 por no constar hasta ahora estar confirmadas por el gobierno el título del remate de las dichas tierras 
La expansión de las haciendas se hizo a expensas del suelo baldío y desocupado de la Corona, así como de las tierras de la Comunidad, como en el caso de la comunidad del Passo. De las 660 fanegadas (alrededor de 1.914 hectáreas) de terreno de valle asignadas durante la visita de 1573, sólo quedaban alrededor de 530 fanegadas (aproximadamente 1.550 hectáreas) en 1715, según una nueva medición realizada por Juan Bravo de Rivero (39). El descenso en las poblaciones de las comunidades indujo a los curacas a arrendar los derechos en usufructo de las tierras comunitarias no explotadas o infrautilizadas, a los españoles, consiguiendo así fuentes suplementarias de ingresos con los que pagar las obligaciones tributarias. Sin embargo, el alquiler de las tierras comunitarias ponía en peligro de usurpación la integridad de la base física de subsistencia comunitaria (40). El monopolio de la tierra y el agua creó fricciones en el seno de los españoles (41) y entre éstos y los miembros de las comunidades (42). Estas relaciones de poder fue lo que estableció el baremo de la vida rural durante gran parte del período colonial.

presentado... no se aprueban ni dejan libres por ahora" AHMC, Actas Notariales, Legajo 9, 1690-1778.

(39) "Los altos de la cordillera que poseen dichos indios son tierras frías y ásperas que sólo les sirven para pastos; por manera que, sumadas todas las fanegadas de tierras de labor según las partidas antecedentes... quedan líquidas de labor 534 fanegadas y 21 almudes, poco más o menos. Y de ellas posee cuatro fanegadas un indio nombrado Pedro de la Cruz, descendiente de don Francisco Chuquicana, cacique que fue del dicho pueblo del Passo", AHAC, Notaria Eclesiástica, Legajo 2, Expediente 17, folio 13.

(40) En su defensa contra el pleito interpuesto por los indios del Passo, Jerónimo de Ondegardo arguyó que "si ahora dicen que les ha faltado el agua no es por falta de ella, sino porque los caciques han arrendado mucha cantidad de tierras que tienen junto al dicho pueblo a algunos españoles, como son Cristóbal de Arévalo y Juan Bustillo en compañía del corregidor Miguel Ruiz de Bustillos y Francisco Vélez su teniente y otros españoles, adonde han sembrado cada un año en cantidad de trescientas fanegas de trigo y cincuenta de maíz" AHMC, Expedientes Judiciales, AR 1540, 1568-1674.

(41) El empleo de la violencia en disputas entre españoles era crónica; en septiembre de 1608, el representante de Jerónimo de Ondegardo declaraba que "don Miguel de Cabrera, encomendero del Passo, y su hermano que fueron la semana pasada y otras veces, toman toda el agua y sin dejar nada para el riego y uso de las tierras y de la chacra de Gerónimo de Ondegardo y molinos, de mano armada", AHMC, Expedientes Judiciales, AR 1540, 1568-1674.

(42) A comienzos del siglo XVIII los indios del Passo incoaron un proceso judicial contra los jesuitas, propietarios de Paucarpata, sosteniendo que éstos los conminaban a un servicio personal forzado. En el informe resultante, el corregidor se expresaba en los siguientes términos "hallé que resulta dicha queja de que por el herbaje y pastos de los ganados mansos que pastean dichos indios y común del pueblo de Santiago del Passo en tierras pertenecientes a Paucarpata y Marquina, le's compelían a que lodas las yuntas de bueves que tienen les vayan a hacer la labranza" AHAC, Notaría Eclesiástica, Legajo 2, Expediente 17, 1715. 
La obtención de un título de propiedad depurado sobre la ticrra constituía un factor importante para la consolidación de la estructura agraria da Valle Bajo. El reclutamiento de una mano de obra de confianza era otro. Así, por ejemplo, un contrato que establecía una sociedad a corto plazo para la explotación de la hacienda de Paucarpata en 1674, señala la utilización de varias formas de mano de obra. En ese año, Nicolás de Escobar y Olmedo, un importante miembro de la nobleza local y marido de la propietaria de esa hacienda, firmó el contrato de explotación de Paucarpata con Pedro Terán de los Ríos, un alcalde ordinario de la Villa de Oropesa (43). Las cláusulas del contrato estipulaban la cuantía del alquiler de las tierras de regadio de la hacienda en una anualidad de 14 pesos por fanegada de suelo. La extensión de los terrenos incluidos en las condiciones del contrato debía basarse en la cantidad de suelo en la que podian plantarse medidas de semilla de secano. Una cláusula del contrato hacía responsable al terrateniente del pago de sínodos para un sacerdote "y demás cosas tocantes a la chacra», lo que hace pensar en la presencia de yanaconas con respecto a la propiedad, cuya instrucción religiosa justificaba un gasto suplementario a cargo del terrateniente. En fecha posterior (1692), la hacienda de Paucarpata disponía de una mano de obra permanente de 43 yanaconas censados (44). Además de los yanaconas, cuyo salario no debía incluirse en los gastos de producción, había que pagar a

(43) Extracto de un contrato para la explotación conjunta de la hacienda de Paucarpata establecido el 3 de febrero de 1674, por el capitán Nicolás de Escobar y Olmedio y don Pedro Terán de los Ríos, alcaldes ordinarios de la Villa de Oropesa:

"Que de las tierras que se sembraren así de trigo como de maíz ha de pagar el dicho don Pedro Terán de los Ríos la mitad, a razón de siete pesos la fanegada. Cuya cuenta se ha de ajustar por las fanegadas de trigo que se sembraren, que se ha de entender cinco fanegas sembradas de trigo por una fanegada de tierra $y$ las que se sembraren de maíz como ellas son, una fanega de maíz por una fanegada de tierra... Y el trigo y maíz que se sembrare ha de poner cada uno la mitad... Y asimismo los indios, bueyes, hierro, aperos, rejas, deshierbos, barbechos, siegas, trillas y demás gastos que se hiciesen han de ser por mitad, y si alguno pusiere más que otro, ajustada la cuenta se ha de satisfacer y pagar al tiempo de la cosecha... Lo que Dios Nuestro Señor fuese servido de dar se ha de partir de por mitad... Y la paga de ceensos, sinodos y demás cosas tocantés a la chácara, queda a cargo del dicho Capitán Nicolás de Escobar, por cuanto el dicho don Pedro de los Ríos paga la mitad de las tierras", AHMC, Actas Notariales, Legajo 101, 1696-1776. El subrayado es nuestro.

(44) Según el censo de 1692 de las haciendas de yanaconas de Cochabamba, existian nueve haciendas en la jurisdicción del Passo, con un total de 428 yanaconas. Paucarpata, que pertenecía a los jesuitas, disponía de una plantilla permanente de 43 yanaconas. 
los trabajadores temporeros en dinero y especies (45). Existen otros datos indiciarios del crecimiento en importancia de la mano de obra rural de carácter estacional en Valle Bajo, la cual estaba desvinculada, de hecho, de la tierra y de los medios de producción. El reclutamiento de mano de obra rural en el siglo diecisiete se hacía entre trabajadores permanentes, yanaconas y un número aumentativo de trabajadores temporeros. Como podrá observarse en la sección siguiente, el sistema de arrendatarios de servicio, apoyado por hornadas de mano de obra estacional, ha constituido una práctica predominante en las haciendas de Cochabamba hasta muy entrado el siglo veinte.

El auge del suelo durante la segunda mitad del siglo diecisiete, resultante del establecimiento de títulos de propiedad legales y depurados, y del desarrollo de una mano de obra sólida, afectó también a la hacienda de Paucarpata. Hacia mediados de la década de 1690, los jesuitas adquirieron Paucarpata a través de un intermediario, y confirmaron el título de propiedad en una visita en 1715 que aportó luz a la disputa en torno a los límites de las tierras sujetas a litigio, y al conflicto sobre los derechos de aprovechamiento de las aguas en el distrito del Passo (46). La adquisición de la hacienda de Paucarpata por los jesuitas constituye una clara demostración de que el proceso secular de consolidación de la estructura colonial de la propiedad de la tierra en Valle Bajo había terminado, y que el suelo constituía una buena inversión a finales del siglo diecisiete. Los jesuitas en particular, sin olvidar otras órdenes regulares, tanto masculinas como femeninas, establecidas en Villa de Oropesa, se convirtieron en una

(45) La mano de obra flotante que encontraba trabajo temporal en las haciendas $y$ en las chacras era grande, y de origen diverso. La incorporación de esos trabajadores en el mercado laboral local fue, en gran medida, obligada debido a la necesidad de pagar tributo en plata. Por un contrato laboral entre los curacas de la comunidad de las tierras altas de Toledo, y Alvaro López de Soria, terrateniente y alcalde ordinario de la villa de Oropesa, firmado el 15 de junio de 1654, cabe observar que las tierras de labor en propiedad de la comunidad situadas en el Asiento de Machacamarca, Valle Bajo, eran explotadas por nueve familias. Cuando los curacas llegaron para cobrar el tributo de las nueve familias, los indios se vieron imposibilitados de pagar. El contrato estipulaba que "reconvinieron y concretaron... en que los dichos nueve indios sirvan por un tiempo de un año al dicho Alvaro López de Soria, en beneficio de sus chacras de Machacamarca y tierras que fueron de los indios del Passo. |El salario iba a ser de 36 pesos por indio por año, $y$ el terratenientel se obligo a dar a cada uno de ellos una pieza de ropa de abasica y una carga de sembradura de maíz donde siembren su chacra $y$ bueves, rejas $y$ aperos para cllos $y$ hacer buen tratamiento", AHMC, Actas Notariales, Legajo 79, $1653-16.56$.

(46) AHMC. Actas Notariales. Legajo 92, 1672-1697; y AHAC Notaría Eclesiástica. Legajo 2, Expediente 17, 1715. 
fucra de primera línea en la economía rural de la región, primeramente a través de censos (derechos de retención que producían ingresos) sobre haciendas y chacras. El peso muerto de los censos impuestos a las haciendas durante el período de prosperidad minera de Potosí debilitó a la nobleza terrateniente de Cochabamba durante el siglo dieciocho. Las órdenes regulares buscaban una fuente segura de ingresos como soporte de sus distintas actividades religiosas y de la calidad de vida a la que estaban acostumbrados sus miembros. Los jesuitas consideraban Paucarpata y sus otras propiedades rurales existentes en la región como unas inversiones bastante rentables.

Es probable que Paucarpata volviera a propiedad laica tras la expulsión de los jesuitas del imperio español en 1767 y 1768. Varias familias fueron las propietarias de la hacienda de Paucarpata durante el siglo diecinueve, la cual fue parcelada en 1883 con fines hereditarios. Entre la década de 1820 y 1867, los herederos de Pedro Ferrufino regentaron la propiedad en un régimen de posesión no dividida o pro-indivisa (47). Seguía resultando rentable dirigir la hacienda como una simple unidad de producción, cuyos beneficios eran distribuidos, a modo de acciones, entre los propietarios comunes. En una fecha indeterminada entre 1867 y 1883, Pol, familia de terratenientes durante la primera época de la república, adquirió la hacienda. En 1828, un tal Antonio Pol poseía la hacienda Falsuri, situada en el Cantón de Quillacollo en Valle Bajo. En fecha indeterminada entre las décadas de los cuarenta y los sesenta, es posible que un tal Hipólito Pol hubiera comprado Paucarpata a los herederos de Ferrufino (48). En 1883, Josefa de Pol —quizás la viuda de Hipólitofalleció, y sus tres hijos dividieron Paucarpata en otros tantos "suyos" o sectores, basándose en la desigualdad de las acciones que poseían. Paucarpata representaba el $47.1 \%$ del valor de una propiedad que se componía de varias casas en la ciudad de Cochabamba, bienes personales, así como terrenos rurales localizados en distintos lugares de Valle Bajo (49).

Es posible que los Ferrufinos experimentaran dificultades financieras durante la década de los sesenta, si no antes. Los datos disponibles indican que los propietarios de Paucarpata empezaron a vender pequeñas parcelas de tierra, desgajándolas del cuerpo de la propiedad hacia 1860 (ver tabla 4), con lo que la

(47) Patrones de tributarios, ANB. Provincia de Tapacari, 1828, 1844 y 1867.

(48) Idem.

(49) JACKSON, Markets, [1], págs. 49-50. 
superficie registrada de la hacienda sufrió la correspondiente reducción. En la tasación realizada a la muerte de Josefa de Pol, se registró una superficie de 749.48 .89 hectáreas de tierra en Paucarpata, además de una estancia, sin medir todavía, en Sierra Tunari, que dominaba Valle Bajo (50), lo que es indicativo de una reducción en su superficie de hasta un $9.4 \%$ con respecto al área registrada a comienzos del siglo dieciocho.

Los herederos de Pol tuvieron que enfrentarse en la década de los noventa a las mismas dificultades financieras que muchos otros terratenientes de Cochabamba; mercados restrictivos y competencia por parte del incipiente sistema de importación de granos, el aumento del nivel de la deuda, y crisis ecológicas periódicas que dañaban o arruinaban cosechas enteras (51). Un heredero, Manuel Pol, tuvo que vender su parte de la hacienda de Paucarpata en condiciones desfavorables. La creciente presión económica se reflejó claramente en la decisión adoptada en 1893 de abandonar la explotación directa de la hacienda en favor de su arriendo (52). Dos años más tarde, en 1895, Manuel Pol hacía publicidad para la venta de sus tierras en Paucarpata, solicitando

CuAdro 4. VENTAS DE TIERRA EN LA HACIENDA DE PAUCARPATA, 1860-1899

\begin{tabular}{|c|c|c|c|c|c|c|c|c|}
\hline $\begin{array}{l}\text { Superficie } \\
\text { en hectar. }\end{array}$ & $\begin{array}{l}0- \\
.99\end{array}$ & $\begin{array}{c}1- \\
4.99\end{array}$ & $\begin{array}{c}5- \\
9.99\end{array}$ & $\begin{array}{c}10- \\
19.99\end{array}$ & $\begin{array}{c}20- \\
49.99\end{array}$ & $\begin{array}{c}50- \\
99.99\end{array}$ & $100+$ & $\begin{array}{c}\sin \\
\text { datos }\end{array}$ \\
\hline \multicolumn{9}{|l|}{ años } \\
\hline $\begin{array}{l}1860- \\
1869 \\
1876\end{array}$ & 7 & 12 & 0 & 1 & 0 & 0 & 0 & 1 \\
\hline $\begin{array}{l}1885 \\
1890\end{array}$ & 4 & 5 & 2 & 2 & 0 & 0 & 0 & 0 \\
\hline 1889 & 13 & 6 & 1 & 0 & 1 & 0 & 1 & 2 \\
\hline TOTAL & 24 & 23 & 3 & 3 & 1 & 0 & 1 & 3 \\
\hline
\end{tabular}

Fuente: Actas Notariales de Cochabamba y Quillacollo. Archivo Histórico Municipal de Cochabamba, Bolivia.

(50) Ide'm, pág. 49.

(51) Jackson, Decline $|1|$.

(52) El Heraldo, Cochabamba, 7 de marzo de 1893. 
un precio de 34.000 Bs (53). El mercado del suelo estaba saturado por aquella época, y Pol no recibió el precio solicitado. Por contra, Manuela Urey de Salamanca, matriarca de la familia de los Salamanca, que poseía amplias extensiones de terreno en otras zonas de Valle Bajo (ver cuadros 5 y 6), sólo pagó 26.400 Bs. por la parcela (78\% del precio solicitado) en la primera de

Cuadro 5. TIERRAS DE JOSE SALAMANCA EN VALLE BAJO EN 1890

\begin{tabular}{llr}
\hline \multicolumn{1}{c}{ Distrito/Hacienda } & Número de parcelas & Hectáreas \\
\hline CalaCala & cinco & 4.03 .65 \\
Sumunpaya & siete & 52.62 .09 \\
Pandoja y Pocpocollo & veintidós & 88.45 .31 \\
Collpapampa & siete & 125.48 .26 \\
MolleMolle & dos + estancia & 322.24 .87 \\
Bellavista & una + estancia & 273.87 .27 \\
Montesillo & una +estancia & 155.27 .08 \\
Chapicirca (estancia) & una & $146.43{ }^{\circ}$ \\
Cochacnacollo & dos & 109.42 .47 \\
\hline
\end{tabular}

- Tierras cultivadas, más tierras adicionales no cultivadas utilizadas para pastizales y recogida de materiales de construcción.

Fuente: Escrituras Públicas, Expediente $/=154$, Archivo Histórico Municipal de Cochabamba, Cochabamba, Bolivia.

CUAdRo 6. TIERRAS DE MANUELA UREY DE SALAMANCA EN VALLE BAJO EN 1904

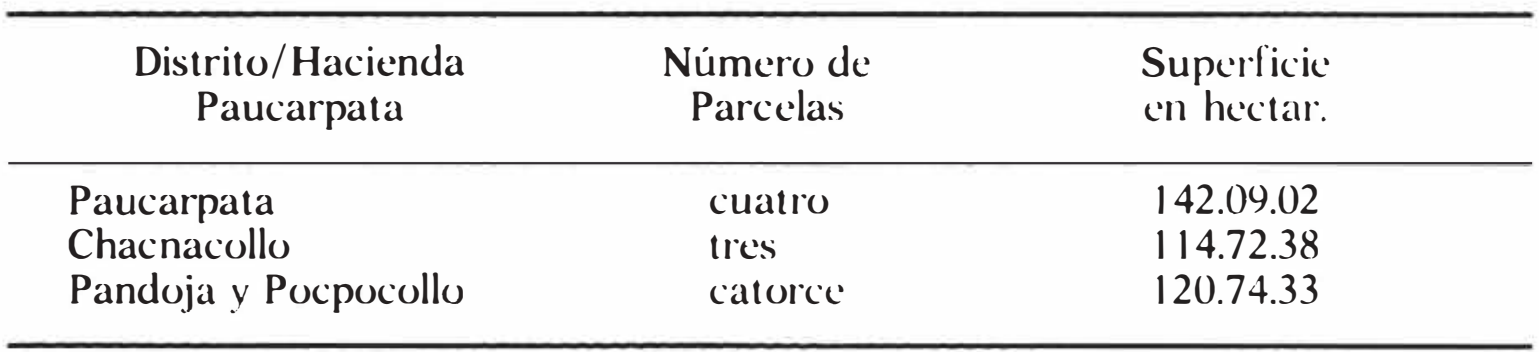

Fuente: Registro de Derechos Reales; Provincia de Tapacari, Provincia de Quilacollo.

(53) El Comercio, Cochabamba, 9 de mar\%o de 1895. 
una serie de adquisiciones que consolidarian su titularidad como propietaria de una gran parte de la hacienda. Manuela Urey de Salamanca compró parcelas adicionales a Manuel Pol y a su hermana Concepción, si bien arrendó el suelo adquirido récientemente en Paucarpata (54). El alquiler de las propiedades rurales por parte de mujeres constituía, al parecer, una práctica corriente en Cochabamba a fines del siglo diecinueve. En nueve años, Manuela Urey de Salamanca adquirió cuatro parcelas en el territorio de la hacienda de Paucarpata con una superficie total de 142.09 hectáreas, o sea un $19 \%$ del área de la propiedad tal como se registra en la tasación de 1883.

La inspección catastral preparada c. 1924 registró sólo una parte de Paucarpata bajo su nombre original. Es posible que se cambiara el nombre de otros "suyos" tras la división de la hacienda, o que éstos mantuvieran una nomenclatura que se les había asignado antes de su incorporación al cuerpo de la hacienda durante el periodo colonial. Sin embargo, los datos existentes muestran el grado avanzado de parcelación de la hacienda. Había cuarenta y una pequeñas parcelas con una superficie de menos de cinco hectáreas, dos propiedades de tamaño medio y una gran finca, que pertenecían, todas, a un miembro de la familia Salamanca (ver Tabla 7). Manuel Saturnino Salamanca, hermano de Daniel Salamanca, heredó las tierras de su madre, en Paucarpata y era el mayor terrateniente del distrito (55).

CUADro 7. ESTRUCTURA DE LA TENENCIA DE LA TIERRA EN (UN SECTOR) DE LA HACIENDA DE PAUCARPATA, C. 1924.

\begin{tabular}{lccrc}
\hline $\begin{array}{c}\text { Superficie de la } \\
\text { parcela }\end{array}$ & $\begin{array}{c}\text { Número de } \\
\text { propiedades }\end{array}$ & $\%$ & Hectáreas & $\%$ \\
\hline $0-99$ & 38 & 84.4 & 12.43 .66 & 5.9 \\
$1-4.99$ & 3 & 6.7 & 7.06 .61 & 3.3 \\
$5-9.99$ & 0 & 0 & 0 & 0 \\
$10-19.99$ & 1 & 2.2 & 14.87 .60 & 7.0 \\
$20-49.99$ & 2 & 4.4 & 82.61 .02 & 38.9 \\
$50-99.99$ & 1 & 2.2 & 95.20 .64 & 44.9 \\
TOTAL & 45 & 99.9 & 212.19 .53 & 100.0 \\
\hline
\end{tabular}

Fuente: Catastro de la Propiedad Rústica, Archivo de la Prefectura de Cochabamba, Provincia de Quillacollo. Cantón de Quillacollo.

(54) AHMC, Actas Notariales de Cochabamba y de Quillacollo, 1895, 1896, 1897 y 1898.

(55) APC, Catastro de la Propiedad Rústica, Provincia de Quillacollo, Cantón de Quillacollo. 
La tenencia de tierras en Paucarpata refleja tanto la subdivisión de la antigua hacienda en fincas de superficie media como el aumento en el número de minifundistas que, ya en 1860, habían adquirido tierras en el cuerpo de la hacienda. Un grupo de latifundistas que, o bien habían conseguido superar la crisis de la década de 1890 o bien habían sacado el máximo partido de ella - como hicieron los Salamanca - y adquirieron terrenos en lo que era virtualmente un mercado de compradores, seguía dominando el panorama rural. Sin embargo, los cambios que se habían producido en la economía agraria de Cochabamba desencadenaron un proceso de transformación en la explotación de la tierra y en las condiciones de trabajo de la mano de obra, cambios que se explican con más detalle en la sección siguiente.

\section{CONDICIONES DE TRABAJO DE MANO DE OBRA RURAL Y ECONOMÍA INTERNA DE LA HACIENDA}

El yanaconaje se constituyó en la forma predominante de mano de obra en las haciendas de Cochabamba en los siglos dieciseis y diecisiete, con la contribución suplementaria de una mano de obra estacional o de temporada. La importancia del yanaconaje en el sistema de producción de las haciendas resulta evidente a través de las listas de yanacones descubiertas en los inventarios de las haciendas, como parte de las mercancías que cambiaron de manos en operaciones de venta o de herencia, así como en la inclusión de su valor monetario en dichos inventarios (56).

El descenso de la población india local y la mentalidad señorial de la nobleza terrateniente en fase de formación acentuaron la

(56) La evidencia documental relativa a este aspecto del yanaconaje descubierta en escrituras de venta e inventarios es amplia. Por ejemplo, en la evaluación de la propiedad de Luis de Guzmán en los años de 1660, se observaba que la "chacra de tierras de Anocaraire, el chico, ... que se compone de 64 lanegadas de tierra... las apreciamos a 200 pesos cada una, con la acción de agua, pastos, indios huidos... La chacra nombrada Anocaraire, el grande, que se compone de 106 fanegadas y 26 almudes... 5 fanegadas del camino para abajo, con la acción de 5 indios de visita con sus familias, a razón de 650 pesos cada fanegada... más las 53 fanegadas del camino para abajo a 250 pesos... y 42 lanegadas $y 28$ almudes del camino para arriba a razón de 150 pesos por ser tierras flojas. La chacra de Londo... que quedan 65 fanegadas y 24 almudes... las 14 lanegadas con la acción de los 14 indios de visita y sus familias a 700 pesos cada fanegada... $v$ las 51 fancegadas y 24 almudes a los dichos 300 pesos". AHNC, Expedientes judiciales, Legajo 95, 1661-1665. Cada lamilia de vanaconas recibici generalmente una fanegada de tierra fértil para su subsistencia. 
importancia del vanaconaje, de manera que los yanaconas se convirtieron en una casta separada, ligada a la tierra y definida por un status heredado, que estaba censada como grupo diferenciado de la población general. Sin embargo, a finales del siglo diecisiete, los sondeos empezaron a registrar un gran número de yanaconas que habian huido de las haciendas, y escasísimos nacimientos entre las familias restantes (57). Este fenómeno no supuso un descenso de la producción agrícola o en la población total asentada en los distritos del valle, sino que, por el contrario, reflejó cambios en la estructura social de la región relacionados con la transformación de la agricultura. El siglo dieciocho fue testigo del fortalecimiento de la economía regional interna y de las nuevas orientaciones de los circuitos comerciales como consecuencia del declive en la importancia del mercado de Potosí. La incorporación de los forasteros a las comunidades y a las haciendas, y la presión demográfica sobre las propiedades privadas reflejadas en la fragmentación de las chacras y en la práctica total salvaguarda de las grandes haciendas, constituyeron un terreno abonado para la aparición de cambios espectaculares en la estructura agraria durante el siglo diecinueve, sobre todo para el proceso explosivo de mestización cultural y biológica de la población (58).

Los arrenderos mestizos e indios, que recibieron una parcela de tierra como elemento de subsistencia a cambio de un alquiler pagadero en dinero y en prestaciones personales, sustituyeron a los yanaconas en las haciendas. Si bien las relaciones de servidumbre que habian caracterizado el yanaconaje desaparecieron, surgieron nuevas formas de coerción extraeconómica que vinculaban el peonaje agrícola a los terratenientes, de modo que,

(57) En 1692, 810, (25,8\%) de 3.135 yanaconas inscritos en las haciendas de Cochabamba se encontraban ausentes, 615 de esos ausentes eran hombres de edades entre los 18 y los 50 años, edad plenamente tributaria, lo que significa que un 36 \% de la mano de obra permanente se hallaba ausente. Véase "Proceso de extinción" de GorIDILlo [1]. A comienzos del siglo XIX, 1.393 yanaconas permanecian en Cochabamba, o sea un $3 \%$ de la población india y un $1 \%$ de la población total. La mavoría de los vanaconas vivian en Valle Alto, así como en propiedades eclesiásticas. Véase LaRSON, [1], pág. 197.

(58) Según un estudio sobre la tierra de Valle Bajo en el siglo XVIII el número de propiedades rurales vendidas aumentó durante la centuria si bien la expansión de dicho mercado estaba más relacionada con las crisis ecológicas y la rebelión de Tupac Katari a comienzos de la década de 1780. El precio medio por fanegada aumentó desde 103 pessos en los comienzos del siglo a 115 pesos en los finales, mientras que la superficie media descendió a 5 fanegadas. Véase "Mercado de tierras en el valle central de Cochabamba. Siglo XVIII" de Fanor Meruvia, Revista Estudios-UMSS. Ver asimismo "Mestizaje" de Gordillo Claure y Jackson [1]. 
merced al monopolio sobre los terrenos agrícolas, los beneficios continuaron concentrándose en manos de la nobleza terrateniente local y de los estratos de minifundistas y comerciantes en proceso de formación. Los precios de los granos permanecieron a un nivel muy parecido a los del siglo diecisiete, si bien con una tendencia alcista, mientras que los productos agrícolas eran adquiridos por una población urbana local que orientaba cada vez más sus actividades hacia el sector manufacturero destinado a la exportación (59).

Valle Bajo posee las tierras más fértiles y mejor regadas de Cochabamba, y su clima benigno permite la recogida de, por lo menos, dos cosechas anuales. La selección de las cosechas cultivadas dependía, en parte, de la fertilidad del suelo, del agua disponible, así como de la demanda del mercado y de la rentabilidad de las distintas cosechas. Así por ejemplo, es posible que los propietarios de Paucarpata pusieran un interés particular en la producción de trigo durante la época de auge de Potosí a finales del siglo dieciséis y principios del diecisiete, aunque la producción también se plegaba a las demandas del mercado local. En los últimos años del siglo diecinueve, se siguió una pauta más diversificada de explotación. A mediados de los años noventa, las tierras de la hacienda de Paucarpata estaban parcialmente irrigadas, y producían maíz, trigo, cebada, patatas y otros tubérculos, guisantes, fruta y alfalfa (60). Como ya se ha observado, los prados eran arrendados a propietarios de ganado dedicados a la transhumancia estacional entre los valles y las tierras altas de Ayopaya, o que descendian con sus animales a Valle Bajo, procedentes de las minas del altiplano (61). En la década de 1920, los propietarios de los distintos sectores de la hacienda primitiva producían trigo, maíz, cebada, patatas y otros tubérculos, guisantes y habas, uvas, manzanas y melocotones (62).

La economía interna de la hacienda de Cochabamba dependía de un suministro abundante de mano de obra barata en el marco de un sistema que se caracterizaba por una tecnología de

(59) Como orientación sobre el movimiento de los precios en Cochabamba en el siglo XVIII consultar "Precios agrícolas en Cochabamba, siglo XVIII", de Luis Rojas. Revista Estudios-UMSS no 4, en prensa. A pesar de su importancia, falta un estudio detallado de la producción y la comercialización del tocuyo, paño de algodón de Cochabamba. Los antecedentes de la industria y el comercio de paños han sido estudiado por Larson [1].

(60) El Comercio, Cochabamba, 9 marzo 1895.

(61) El Heraldo, Cochabamba, 7 de marzo 1893.

(62) APC, Catastro de la Propiedad Rústica. Provincia de Quillacollo, Cantón de Quillacollo. 
escaso vuelo y por el estancamiento de la productividad. Los terratenientes apenas si utilizaban fertilizantes, y la disponibilidad de agua constituía un factor crítico para la producción. Finalmente, los terratenientes consiguieron incrementar sus niveles de producción sometiendo a cultivo parcelas adicionales de tierra dentro del perímetro de la hacienda, sin preocuparse de introducir innovaciones para elevar los niveles de productividad. Dentro de las condiciones de mercado imperantes desde el siglo dieciséis hasta comienzos del veinte, el sistema de producción vigente en las haciendas de Cochabamba resultó efectivo en el contexto del sistema de mercado existente, aunque se mostraba incapaz de adaptarse a los rápidos cambios que experimentaba la demanda.

Como respuesta a la crisis provocada a finales del siglo diecinueve por la contracción de los mercados y la liberalización de las importaciones bolivianas de grano a precios baratos, los terratenientes optaron por deshacerse de sus tierras y venderlas en vez de introducir innovaciones. Por otra parte, muchos terratenientes intentaron aumentar las obligaciones en concepto de servidumbre personal de los arrendatarios de servicio, con objeto de reducir más aún los costos de producción. Algunos latifundistas - los que poseían una capacidad de reserva- intentaron manipular el mercado local y conseguir beneficios inesperados durante los años de escasez real o aparente. Finalmente, tal como ocurrió después de 1918 con el rápido crecimiento de la producción del alcohol en Bolivia, los terratenientes ajustaron su plan de producción a los cultivos más rentables, si bien la demanda del mercado nacional resultaba extremadamente inestable después de la década de 1880, y las finanzas de muchos terratenientes se evaporaron como consecuencia de torpes especulaciones en torno a las condiciones futuras del mercado (63).

Como se ha indicado anteriormente, los inventarios pormenorizados de las propiedades de los Salamanca no contenían referencia alguna a las condiciones de trabajo de la mano de obra en Paucarpata a finales del siglo diecinueve ni a principios del veinte, elemento que se repetiría en el inventario de 1883. Cabe, sin embargo, sacar conclusiones sobre la base de los datos conseguidos con relación a formas de servidumbre laboral en otras haciendas en Valle Bajo, susceptibles, a su vez, de proyectarse sobre el caso específico de Paucarpata. La tenencia de tierra en régimen de servicio persistía en las haciendas, si bien el sistema

(63) Estos puntos fueron objeto de discusión en JacksON [32] sobre todo el capítulo 1 y passim; y en "Mestizaje", págs. 22-25, de Goridlı.o. 
empezó a derrumbarse con los cambios acaecidos en la estructura de la economía agraria de Cochabamba a finales del siglo diecinueve. La hacienda de Montecillo, que también pertenecía a José de Salamanca en 1890, era un caso típico de las relaciones laborales vigentes en haciendas de Valle Bajo, y es muy posible que imperara el mismo sistema de tenencia de tierras en régimen de servicio en Paucarpata. Entre las obligaciones específicas se incluia la plantación, la escardadura, y la recolección de cosechas cultivadas en la tierra solariega, la depuración del sistema de irrigación de la hacienda, y el transporte de la producción agrícola al mercado designado por el terrateniente, la provisión de leña en beneficio de éste, así como la prestación de servicios personales (pongueaje) por un salario semanal de 2 reales. En compensación, los arrendatarios recibían una parcela de tierra en usufructo como garantía de subsistencia, cuya superficie dependía del alquiler pagado en dinero y en prestaciones laborales facilitadas al terrateniente (64).

El arriendo en régimen de servicio y mano de obra de la hacienda cambió a finales del siglo diecinueve y a comienzos del veinte. Los datos de los que se dispone hacen pensar que podría haber aumentado la importancia de la aparcería, circunstancia que desplazó gran parte de los costos y de los riesgos de producción a cargo del arrendatario. Por otra parte, el número de arrendatarios de servicio cayó como consecuencia de la migración procedente de Cochabamba y de la adquisición de tierras por parte los arrendatarios. Así por ejemplo, a finales del siglo XIX, llegaban a 8.000 los arrendatarios de servicio en haciendas de la provincia de Tapacari (secciones de Valle Bajo y del Cantón de Tapacari en las vecinas tierras altas), sin perjuicio de que esa cifra bajara a 4.567 en la segunda década de este siglo (65). Esto no significa que las relaciones laborales permanecieran estables o cambiaran en las distintas secciones de Paucarpata, aunque el cambio al régimen de aparecería constituyera una respuesta racional ante la inestabilidad de los mercados.

\section{CONSIDERACIONES FINALES}

La evolución de la estructura agraria en Valle Bajo en los

(64) "Evolución y Persistencia", pág. 135, de Jackson.

(65) Ibied, págs. 157-158. 
siglos dieciséis y diecisiete se movió por los cauces observados en otras partes de la región andina y de la América colonial española (66). Colonizadores criollos importantes, en algunos casos arrendatarios de haciendas, hicieron constar su interés por tierras situadas en distritos contiguos a ayuntamientos, por tratarse de una fuente importante de mano de obra durante el período de desarrollo económico de la región. Por otra parte, los colonizadores se sirvieron de su influencia y de autoridad sobre el gobierno municipal para acelerar el desarrollo de sus operaciones agrícolas.

En el caso específico examinado aquí, Juan y Gerónimo de Ondegardo, arrendatarios de la encomienda de Santiago del Passo, utilizaron su influencia para conseguir una resolución favorable por parte de los funcionarios reales en torno a las tierras en litigio y a los derechos sobre el aprovechamiento de las aguas, y consolidaron su dominio sobre las parcelas fértiles del valle, las cuales formaban el núcleo de una hacienda que extraía mano de obra de su encomienda. Juan Polo de Ondegardo se sirvió de su influencia para obtener una disposición favorable sobre los límites de la comunidad del Passo, y en apoyo de sus títulos sobre el agua procedente del río Patata, la cual resultaba vital para la explotación de sus molinos y el desarrollo de sus actividades agrícolas. Gerónimo de Ondegardo se vio favorecido por un reajuste ventajoso de sus títulos de propiedad durante la visita de 1593.

El aumento en la demanda de productos alimenticios en Potosí a finales del siglo dieciséis y comienzos del diecisiete, fomentó en Cochabamba la explotación agrícola, con fines comerciales, lo que, unido al descenso de la población entre las comunidades indias, contribuyó al proceso de usurpación de las tierras comunitarias. Los terratenientes españoles poseían, en muchos casos, títulos de propiedades defectuosos, por lo que se aprovecharon de la visita y composición de tierras del año de 1645 para recibir unos títulos depurados. Los años inmediatamente siguientes a la visita de 1645 fueron testigo de un incremento en la demanda de pequeñas parcelas de terreno, así como de la consolidación de un sistema de tipo mixto. Las comunidades y grandes haciendas

(66) Sobre Bolivia, véase "The decline" Jackson, [1], "Economic Change" de LANGER [1] "Oprimidos" de Rivira. [1] y "Las haciendas y la reforma agraria en el altiplano de Bolivia: Su reevaluación", de Daniel HEYDUCK; en Emohistoria 1974, n" 13, págs. 1-11. Por lo que atañe al cambio de modelos en la tenencia de la tierra en San Luis de Potosí, México, consultar Cinco haciendas mexicanas. Tres siglos de vida rural en San Lais de Potosi, 1600-1910, de Juan Bazant, México, 1975. 
ejercian dominio sobre las tierras mejor irrigadas próximas a la cordillera, mientras que los chacareros poseían parcelas pequeñas y medias, más alejadas de las fuentes de aguas principales. La mayoría de los conflictos giraba en torno a problemas con las tierras y el agua, y los jefes de la comunidad explotaron hábilmente el sistema legal español en defensa de sus propios intereses y de los de las comunidades.

Sin embargo, la política colonial española, destinada a subvencionar la economía minera de Potosí, y a debilitar a los encomenderos, provocó cambios estructurales significativos en el mundo andino, que alteraron el desarrollo de la estructura agraria de Cochabamba. El repartimiento por sorteo de la mano de obra disponible (mita) y la creciente presión tributaria dieron origen a una migración en gran escala en el Antiplano, así como entre éste y los valles orientales, incluyendo Cochabamba. La afluencia de campesinos clasificados por el Estado colonial en forasteros o mestizos, fue preludio de los cambios estructurales que iban a producirse en el sistema agrario de Cochabamba. Un número cada vez mayor de forasteros se afincó en las comunidades y chacras, modificando el sistema de mano de obra servil conocido como yanaconaje, y dando origen en el siglo dieciocho a la aparición del arrendamiento de servicios en las haciendas. El campesinado de Cochabamba, que no estaba vinculado a la estructura comunitaria con sus consiguientes obligaciones fiscales frente al Estado colonial, se desprendió del status de indio y, en parte notable como consecuencia de su intensa participación en las economías local y regional, se forjó un status socio cultural de mestizo perfectamente diferenciado.

El descenso en importancia del mercado de Potosí en el siglo dieciocho condujo a una redefinición de los circuitos comerciales y a cierta diversificación económica, con el desarrollo, por ejemplo, de la producción textil con fines comerciales. Sin embargo, el mayor cambio en la estructura agraria de Cochabamba tuvo lugar a fines del siglo diecinueve, como resultado de la liberalización del mercado nacional boliviano y de la pérdida por los granjeros de Cochabamba de sus mercados tradicionales del Altiplano. El arrendamiento en régimen de servicio, que constituía la forma predominante de la mano de obra en los siglos dieciocho y diecinueve, cayó en importancia en el siglo veinte, y muchos terratenientes perdieron algunas o todas sus propiedades en virtud de las difíciles condiciones económicas existentes a fines del siglo diecinueve, exacerbadas por los crecientes niveles de en- 
deudamiento y el aumento de las tasas de contribución territorial. El Estado holiviano abolió el régimen de protección del status legal, así como propiedades comunitarias, como consecuencia de lo cual el suelo de las comunidades se fragmentó rápidamente.

La hacienda de Paucarpata cambió, frecuentemente, de propietarios durante el período colonial, si bien permaneció intacta hasta su división por razones de herencia en 1883. Los titulares de la hacienda en la década de los ochenta, miembros de la familia Pol, se vieron arrastrados por la crisis de los años noventa, y forzados, por ende, a parcelar sus terrenos y venderlos a precios desfavorables. Muchos, si no casi todos los terratenientes de Cochabamba anteriores a 1870 , perdieron sus propiedades en los años noventa. El cambio experimentado en la política india condujo a la creación de algunas haciendas de media y gran superficie a partir de las tierras comunitarias de Passo, sin perjuicio de que antiguos miembros de la comunidad, campesinos carentes de tierras y residentes urbanos, adquirieran también o rehusaran desprenderse de una parte considerable de esas propiedades. Algunas familias, como los Salamanca, sacaron partido de la crisis económica de los noventa y del desarrollo del mercado en antiguas tierras comunitarias para la adquisición de grandes propiedades que, no obstante, no siempre administraron como simples unidades de producción. Simultáneamente, la crisis en la economía agraria de Cochabamba en los últimos años del siglo diecinueve contribuyó a la fragmentación de las tierras agrícolas en el Cantón del Passo y de Valle Bajo, así como a la aparición de una nutrida clase de minifundistas. El desarrollo de la propiedad de la tierra y de las relaciones sociales de la vida rural en Cochabamba evolucionó en paralelo, en ciertos aspectos, con la transformación del régimen de posesión de la tierra en otras regiones de Iberoamérica durante el período colonial. El poder y la influencia de los colonizadores españoles, así como la connivencia de los funcionarios reales locales resultaron factores básicos en el proceso de constitución de las haciendas y de obtención de los derechos de explotación de todas las fuentes de agua importantes. Los terratenientes españoles usurparon las tierras comunitarias, si bien las poblaciones residentes en ellas, notablemente mermadas, retuvieran el control sobre un área suficiente que les garantizara unos niveles mínimos de subsistencia. Las visitas y las composiciones de tierras, el examen judicial de los títulos de propiedad, así como la validación de los títulos defec- 
tuosos, constituveron una de las medidas fundamentales en la consolidación de los esquemas de propiedad de la tierra.

En los últimos años del siglo XIX, la travectoria de la historia rural de Cochabamba se distinguió de la de otras muchas regiones de Iberoamérica en las que se incluían otras zonas de Bolivia. Los cambios estructurales en la economía boliviana posteriores a la institución de una política de libre comercio, y la terminación del primer ferrocarril entre la costa y el altiplano trajeron consigo la división de las haciendas coloniales y coincidieron con la política de subparcelación de las tierras comunitarias. En Cochabamba, las tierras comunitarias y las haciendas se subdividieron de manera que el minifundio campesino creció no sólo en número sino en importancia. En otras regiones de Iberoamérica, las haciendas se extendieron a finales del siglo diecinueve, y la invasión de las tierras comunitarias se tradujo en la expansión de las haciendas a expensas de las antiguas tierras de la comunidad. Por ejemplo, en otras regiones de Bolivia como, por ejemplo, el altiplano, las haciendas se extendieron, absorbiendo las tierras comunitarias e incorporando los antiguos miembros de la comunidad a la mano de obra de la hacienda. De igual manera, las haciendas en ciertas zonas de México, tales como San Luis Potosí, crecieron a fines del siglo diecinueve al unísono con la apertura de nuevos mercados, producto, a su vez, de la terminación de las obras de los ferrocarriles. Por los años treinta de nuestro siglo, existía en los distritos del valle de Cochabamba una clase, cada vez más politizada y beligerante, formada por campesinos terratenientes, conocida como los piqueros. 